\title{
O Impacto dos Acordos de Investimentos sobre os Estados-Membros do Mercosul
}

\author{
Umberto Celli Junior*
}

Resumo: A participação de países em desenvolvimento, dentre os quais os do Mercosul, de acordos de investimentos não constitui fator determinante na maior ou menor atratividade de Investimentos Estrangeiros Diretos (IED). Além disso, as atuais propostas de liberalização dos investimentos internacionais no plano multilateral (MAI) da OMC ou no regional da ALCA são muito direcionadas em favor dos países desenvolvidos. 0 que se procura demonstrar é que, para os países em desenvolvimento, o desafio mais importante é encontrar um equilíbrio entre a contribuição potencial dos Acordos de Investimentos para o aumento da atratividade dos investimentos e a preservação do espaço e da capacidade de perseguir políticas industriais orientadas para o desenvolvimento.

Palavras-chave: Investimentos Estrangeiros Diretos (IED), Política Industrial e de Desenvolvimento, Medidas de Investimento Relacionadas ao Comércio - TRIMS.

Abstract: The participation of developing countries, including Mercosur members, in Investment Treaties is not a crucial factor to determine the degree of attractiveness of Foreign Direct Investment (FDI). Moreover, the liberalization proposals currently tabled at the multilateral level in the WTO or at the regional level in the FTAA are very much intended to favor the developed countries. It is submitted that the most important challenge for developing countries is that they are able to strike a balance between the potential contribution of Investment Treaties to enhance the attractiveness of FDI and to maintain space and capability of pursuing industrial policies oriented to their development.

Keywords: Foreign Direct Investment (FDI), Development and Industrial Policy, Trade Related Investment Measures-TRIMS.

\footnotetext{
Professor de Direito Internacional da Universidade de São Paulo, Brasil. Advogado em São Paulo. Membro da Comissão de Pós-Graduação do Programa de Pós-Graduação em Integração da América Latina - PROLAM/USP. 0 autor dedica esse artigo ao eterno mestre e amigo Professor Guido Fernando Silva Soares. Email: umbcelli@usp.br
} 


\section{Introdução}

Em 2004, conforme índices divulgados por uma empresa de consultoria internacional, o Brasil caiu da 9 a para a 17 a posição na lista de países com potencial de atratividade para investimentos estrangeiros diretos ("IED"). Muita embora a alta carga tributária, a enorme burocracia, o crédito caro, a má distribuição de renda, o baixo nível de poupança e o ambiente regulatório tenham sido destacados como alguns dos fatores responsáveis por essa queda, esses índices suscitam questōes e propiciam reflexōes sobre a regulamentação dos investimentos internacionais, seja em foros multilaterais como a $\mathrm{OMC}$ ou regionais como a ALCA.

Trata-se a regulamentação dos investimentos internacionais de tema controvertido que tradicionalmente tem dividido países desenvolvidos e em desenvolvimento. Basta lembrar das disposições da Carta de Havana que, em larga medida, contribuíram para o fracasso da criação da Organização Internacional do Comércio na década de 40. A tentativa de alguns países desenvolvidos de negociar em meados dos anos 90 um Acordo Multilateral de Investimentos ("MAI") no âmbito da Organização para a Cooperação e o Desenvolvimento Econômico (“OCDE”) constitui outro exemplo importante. Mais recentemente, na Rodada de Doha da OMC, que teve início em 2001, o assunto, introduzido na pauta da Conferência Ministerial de Cingapura, em 1996, foi objeto de intensas negociaçôes sem que se tenha chegado ainda a um consenso. Da mesma forma, nas negociações do Mercosul com a União Européia e do Mercosul com os Estados Unidos no âmbito da ALCA, ambas adiadas para 2005, a regulamentação dos investimentos tem provocado intermináveis e acalorados debates.

Essa dificuldade em se firmar acordos sobre regras de investimentos tem levado, ao longo dos anos, à conclusão de acordos bilaterais. Desde 1959, quando a Alemanha celebrou seu primeiro Tratado Internacional sobre Investimentos ("BITs") com o Paquistão e a República Dominicana, o número de tais acordos cresceu significativamente atingindo um total de 385 no final de 1989 e de 2.100 em $2002^{1}$. Os BITs, como explica Cláudia Perrone-Moisés, "são instrumentos através dos quais dois países, geralmente um país desenvolvido e um país em desenvolvimento, procuram regular relações em matéria de investi-

\footnotetext{
${ }^{1} 0$ número de países envolvidos na conclusão de BITs passou de 105 no final de 1989 para 176 em 2002. Com exceção do “Acordo sobre Garantia de Investimentos” firmado com os Estados Unidos em 06 de fevereiro de 1965, promulgado pelo Decreto N. 57.943, de 10 de março de 1966, o Brasil, embora signatário de alguns BITs, não ratificou nenhum deles. Ver a respeito A. BEVIGLIAZAMPETTI/T. FREDRIKSSON, "The Development Dimension of Investment Negotiations in the WTO: challenges and opportunities", in Journal of World Investment, vol. 4, no. 3, junho de 2003, p. 401.
} 
mentos, com a finalidade de aumentar seu fluxo." Em linhas gerais, salienta a autora, o BIT "estipula regras de proteção ao investimento estrangeiro que serão aplicadas após a admissão do investimento e que não constam da legislação interna do país hospedeiro."

No plano regional, os Estados Unidos acabam de firmar com o Uruguai (Estado-Membro do Mercosul) um BIT, o qual, como os demais, visa a promover e a estimular os IED, com a estipulação de mecanismos de proteção contra medidas de expropriação e nacionalização.

Se, de um lado, os BITs podem propiciar potencialmente um aumento dos IED em vários países, ao estabelecerem regras mais transparentes e um ambiente mais seguro para as empresas transnacionais, de outro, eles reduzem a capacidade dos países em desenvolvimento de adotar políticas industriais que criem certas contrapartidas aos investidores estrangeiros, tais como o estabelecimento de metas de exportação ou a exigência de que seus produtos tenham algum conteúdo produzido por empresas nacionais. Como assinala Vera Thorstensen, "as políticas dos governos normalmente incluem incentivos e fornecimento de bens ou serviços em termos preferenciais. Em troca, exigem o cumprimento de certo número de regras como a de conteúdo local, isto é a compra de partes e componentes de fabricação doméstica, ou a de desempenho exportador, isto é, o compromisso de exportar parte dos bens produzidos. Podem também exigir transferência de tecnologia, capital mínimo nacional ou joint ventures". ${ }^{3}$ Assim, para os países em desenvolvimento, o desafio mais importante é, como diz o relatório da UNCTAD de 2003, "encontrar um equilíbrio entre a contribuição potencial desses acordos para o aumento dos fluxos de investimento e a preservação da capacidade de perseguir políticas orientadas para o desenvolvimento que lhes permitam tirar mais benefícios deles" .

Preocupação semelhante à contida no relatório da UNCTAD foi manifestada pelo Ministro de Comércio e Indústria da Índia, Arun Jaitley, no tocante a um possível acordo multilateral de investimentos na OMC, ao enfatizar que os países em desenvolvimento "should not be coerced or compelled to take decisions on a multilateral investment agreement in the WTO unless they are fully convinced it is in their interests". Segundo ele, há um grande receio por parte dos países em desenvolvimento de que regras multilaterais de investimentos possam vir a restringir suas opções de políticas de desenvolvimento agora e no futuro. "They should not foreclose for development countries such

\footnotetext{
Cf. C. PERRONE-MOISÉS, in Direito ao Desenvolvimento e Investimentos Estrangeiros. São Paulo: Ed. Oliveira Mendes, 1998, p. 24.

${ }^{3}$ Cf. V. THORSTENSEN, in OMC - Organização Mundial do Comércio: as regras do comércio internacional e a Nova Rodada de Negociações Multilaterais. 2. ed. São Paulo: Aduaneiras, 2001, p. 102-103.

${ }^{4}$ Relatório de 2003 da UNCTAD disponível em www.unctad.org.
} 
development options that the developed countries themselves had utilized at earlier stages of their development".

O objetivo deste artigo é, pois, o de verificar qual o impacto dos Acordos de Investimentos sobre os países em desenvolvimento, dentre os quais os do Mercosul, em que medida a proteção e a preservação do espaço para adoção de políticas industriais em matéria de IED é, de fato, importante para tais países e até que ponto a não-participação de BITs, de acordos regionais com dispositivos de proteção aos investimentos ou de acordos multilaterais de investimentos lhes pode ser prejudicial a ponto de desestimular seu fluxo ou provocar oscilaçôes na lista de países com potencial de atratividade de IED.

\section{Conceitos de IED e de política industrial}

\section{.IED}

O investimento, na expressão de Luiz Olavo Baptista, "pode ser feito diretamente numa atividade produtiva de bens e serviços, caso em que é chamado de investimento direto, ou ser objeto de uma aplicação financeira, quando é chamado de investimento indireto". Como exemplo de IED, cita o caso de uma empresa transnacional que adquire 55\% das ações de uma mina de bauxita no Brasil; por sua vez, configuraria a hipótese de investimento indireto a aquisição por uma empresa transnacional, em bolsa, de $5 \%$ das açôes de uma mina de bauxita no Brasil. A diferença, pondera o autor, "aparece, então, na possibilidade de controle, ou da atividade de gestão do investidor. Este deve ser um empresário, no caso do investimento direto, e será um aplicador de recursos financeiros, no caso dos investimentos diretos".

Já o Manual sobre Balanço de Pagamentos do Fundo Monetário Internacional (FMI) estabelece um padrão quantitativo de definição dos IED, a saber: "Um investimento direto (empresa) é definido neste Manual como uma empresa, incorporada ou não, em que um diretor investidor, que seja domiciliado em uma outra economia, detenha dez por cento ou mais de suas açóes ordinárias ou poder de voto (para uma empresa incorporada) ou o equivalente (para uma empresa não incorporada).

\footnotetext{
${ }^{5}$ Discurso pronunciado por ocasião da Conferência Internacional sobre Comércio, Investimento e Desenvolvimento organizado pela Índia e UNCTAD e realizado de 18 a 20 de maio de 2003.

${ }^{6}$ L. O. BAPTISTA. Os investimentos internacionais no Direito Comparado e Brasileiro. Porto Alegre: Livraria do Advogado Editora, 1998, p. 30/31.

${ }^{7}$ Ver a respeito B. FIGUEIREDO DIAS. Os impactos dos Acordos Internacionais sobre Investimentos Estrangeiros Diretos na Legislação Brasileira, dissertação de mestrado apresentada à Faculdade de Direito da Universidade de São Paulo em 2004, p. 36.
} 
No Brasil, a Circular No. 2.997, de 15 de agosto de 2000, do Banco Central, em seu artigo 20, conceitua o IED como: "As participações, no capital social de empresas do País, pertencentes a pessoas físicas ou jurídicas residentes, domiciliadas ou com sede no exterior, integralizadas ou adquiridas na forma da legislação em vigor, bem como o capital destacado de empresas estrangeiras autorizadas a operar no País, observado o disposto no art. 10 desta Circular".

\section{-Política industrial}

Trata-se a política industrial de uma política governamental definida pelo Poder Executivo, que faz parte do conjunto de medidas utilizadas pelo Estado no exercício da competência definida no artigo 174 da Constituição Federal, "o poder-dever de regulamentação econômica". Ressalta do artigo 174 a competência em matéria de planejamento econômico, definida por Eros Grau como: "a forma de ação estatal, caracterizada pela previsão de comportamentos econômicos e sociais futuros, pela formulação explícita de objetivos e pela definição de meios de ação coordenadamente dispostos, mediante a qual se procura ordenar, sob o ângulo macroeconômico, o processo econômico, para melhor funcionamento da ordem social, em condiçōes de mercado". 'Das açōes contidas nessa definição extraem-se as principais características da política industrial, quais sejam as de formulação de objetivos e de meios de ação voltados à ordenação do processo econômico em condiçôes de mercado para melhor funcionamento da ordem social.

Como parte indispensável de uma política de desenvolvimento, constitui a política industrial, pois, um conjunto coordenado de ações que envolvem tanto o setor público como o privado, cujo objetivo é o de dotar a indústria de maior competitividade, impulsionando o crescimento econômico e gerando, conseqüentemente, maior oferta de emprego. Exemplo de política industrial é o recente projeto do governo brasileiro de estabelecer certas diretrizes e condiçôes para a implantação da tecnologia de televisão digital no país. Como ainda não dispõe dessa tecnologia, o governo avaliou os modelos do Japão, da

\footnotetext{
${ }^{8}$ Ver V. KLEIN, "Questões acerca de uma Política Industrial do Mercosul”, in Estudos de Direito Internacional, vol. II, org. W. MENEZES, Curitiba, Juruá, 2004, p. 506. Estabelece o "caput” do artigo 174 da Constituição Federal: "Como agente normativo e regulador da atividade econômica, o Estado exercerá, na forma da lei, as funções de fiscalização, incentivo e planejamento, sendo este determinante para o setor público e indicativo para o setor privado".

${ }^{9}$ Cf. E. R. GRAU. Planejamento Econômico e Regra Jurídica. Revista dos Tribunais, São Paulo, 1977, p. 65, apud V.KLEIN, (nota 8), p. 506.
} 
União Européia e dos Estados Unidos. Determinou que fossem realizados estudos sobre as contrapartidas ("offsets") que poderiam ser exigidas pelo Brasil ao optar por uma dessas tecnologias, tais como requisitos de desempenho de exportação, transferência de tecnologia e aquisição ou uso, pelos investidores estrangeiros, de produtos de origem doméstica ou de qualquer fonte doméstica (conteúdo local).

\section{A regulamentação multilateral dos investimentos}

A regulamentação multilateral dos IED é projeto antigo. Durante a Conferência de Bretton Woods em 1944, foi concebido o tripé de sustentação do sistema econômicofinanceiro e comercial global da nova ordem internacional. Pouco tempo depois, seriam criados o Banco Internacional para Reconstrução e Desenvolvimento (BIRD), com a função de financiar a reconstrução dos países atingidos pela Segunda Guerra Mundial, e o FMI com o intuito de assistir países com problemas monetários. Por oposição principalmente dos Estados Unidos, não se chegou a um acordo quanto à constituição de organização internacional, a Organização Internacional do Comércio (OIC), que teria como atribuição precípua regulamentar o comércio internacional, inclusive no tocante aos investimentos internacionais. Em vez da OIC, firmou-se um acordo provisório, com objetivos bem menos ambiciosos, o Acordo Geral sobre Tarifas e Comércio (GATT) de 1947, dispondo apenas sobre a liberalização do comércio de bens (i.e., redução de barreiras tarifárias e não-tarifárias). ${ }^{10}$

O sistema multilateral de comércio sob o GATT foi sendo consolidado por meio da realização de várias rodadas de negociaçôes. Contudo, somente na última dessas rodadas, a do Uruguai, que teve início em 1986, é que o tema investimentos internacionais entrou efetivamente na pauta. Ao longo dos anos, tornara-se prática comum dos Estados, inclusive dos desenvolvidos, condicionar a admissão de IED à realização de determinados objetivos comerciais, o que passou a ser denominado de "obrigaçôes de resultados" ou "requisitos de desempenho" ("performance requirements").

No início dos anos 80, conflito envolvendo os Estados Unidos e o Canadá relativamente a certas "obrigaçôes de resultados" estabelecidas por este último como contrapartida à recepção de IED foi trazido ao precário sistema de solução de disputas do GATT. Insurgiram-se os Estados Unidos contra certos atos administrativos do governo canadense lastreados na lei sobre investimentos estrangeiros vigente naquele país. As autoridades canadenses exigiam, previamente à aprovação da operação de investimento pretendida,

\footnotetext{
${ }^{10}$ Tratou-se, pois, de um "tripé manco", já que constituído de duas organizações internacionais e um acordo provisório que não dispunha, evidentemente, da complexidade institucional daquelas.
} 
que os investidores estrangeiros assumissem os seguintes compromissos: (i) instalação de fábrica e produção local dos bens a serem comercializados no Canadá; (ii) aquisição de componentes canadenses para a produção desses bens (i.e., fornecimento local); e (iii) exportação desses bens. O governo dos Estados Unidos entendeu que tais exigências eram incompatíveis com uma série de dispositivos do GATT, dentre os quais os parágrafos $4^{\circ}$ e $5^{\circ}$, do artigo III, e parágrafo 1 (c), do artigo XVII:

\section{"Artigo III}

4. Os produtos do território de uma parte contratante que entrem no território de outra parte contratante não usufruirão tratamento menos favorável que o concedido a produtos similares de origem nacional, no que diz respeito às leis, regulamento e exigências relacionadas com a venda, oferta para venda, compra, transporte, distribuição e utilização no mercado interno...

5. Nenhuma parte contratante estabelecerá ou manterá qualquer regulamentação quantitativa interna que se relacione com a mistura, transformação ou utilização de produtos em quantidades ou proporçōes determinadas, e que exija, direta ou indiretamente, of fornecimento, pelas fontes produtoras nacionais, de quantidade ou proporção determinada de um produto enquadrado na regulamentação...

\section{"Artigo XVII}

c) Nenhuma parte contratante impedirá qualquer empresa (quer se trate ou não de uma empresa mencionada na alinea a) do presente parágrafo) [empresas estatais] sujeita à sua jurisdição, de agir de acordo com os princípios enunciados nas alíneas a) $e$ b) do presente parágrafo [não discriminação e compras e vendas inspirando-se unicamente em consideraçōes de ordem comercial, inclusive no que diz respeito às quantidades disponíveis e livre concorrência, respectivamente].

O Painel constituído para o caso manifestou posição segundo a qual estaria fora da competência do GATT (i.e., inexistência de mandato específico) o exame da compatibilidade da primeira das condiçôes impostas pelo governo canadense, qual seja a produção local de bens que de outra forma seriam importados, com os parágrafos transcritos acima.

\footnotetext{
${ }^{11}$ "Le Groupe Spécial a considerée que l'examen que demandaient les Etats-Unis des engagements de fabriquer des produits qui, autrement, seraient importés, n'entrait pas dans son mandat, qui ne mentionne que"les achats de marchandise au Canada et/ou les exportations de marchandises du Canada". Par conséquent, il n'a pas examinécette question”. Ver D.CARREAU/PJUILLARD, in Droit International Économique, $4^{\mathrm{a}}$ edição, Paris, L.G.D.J, 1998, p.174.
} 
Limitou-se a examinar as duas outras condiçōes: fornecimento local e exportação. Quanto à primeira, $\mathrm{o}$ Painel entendeu tratar-se de exigência incompatível com o parágrafo $4^{\circ}$, uma vez que não havia garantias de que os produtos originários de outras Partes Contratantes pudessem receber o mesmo tratamento que os produtos manufaturados e fornecidos por empresas locais. O Painel, no entanto, não considerou ser tal condição incompatível com o parágrafo $5^{\circ}$. No tocante às obrigaçōes de exportação, o Painel ressaltou que condicionar autorização de investimento estrangeiro ao compromisso do investidor de exportar determinada quantidade ou proporção de sua produção não violava nenhum dos princípios de não-discriminação do GATT.

Essa controvérsia entre Estados Unidos e Canadá e a solução que lhe foi dada pelo Painel serviram de apoio à retomada das negociaçóes acerca da regulamentação dos IED durante a Rodada Uruguai do GATT (1986-1994). Já estava claro à época, como lembra Cláudia Perrone-Moisés, que o GATT “era inadequado para regular as novas realidades comerciais. Dentre elas, as mais importantes, as questōes dos investimentos e dos serviços". ${ }^{2}$ Por outro lado, à medida que evoluíam essas negociações, também ficavam evidentes as divergências entre os países desenvolvidos e os em desenvolvimento em torno do assunto. $\mathrm{O}$ objetivo dos primeiros era o de estabelecer regras que limitassem amplamente a capacidade de atuação dos governos (notadamente os dos países em desenvolvimento) sobre os investimentos estrangeiros, ou seja, restringir a capacidade de adoção de medidas de adequação destes investimentos aos interesses políticos e econômicos nacionais. Os países em desenvolvimento, ao contrário, buscavam a manutenção de padrões mínimos de regulação, ou seja, a manutenção do espaço para realizar políticas de incentivo ao seu desenvolvimento industrial.

Os resultados das negociações da Rodada Uruguai concluída em dezembro de 1993 foram formalmente adotados em Marraqueche em abril de 1994. Criou-se a OMC, que entrou em operação em 1995, composta por vários acordos e regras de comércio internacional, inclusive no que se refere a investimentos internacionais. Se, de um lado, o Acordo

\footnotetext{
${ }^{12}$ C.PERRONE-MOISÉS, (nota 2), p. 39.

${ }^{13}$ Segundo V. THORSTENSEN, "a intenção inicial dos países desenvolvidos, especialmente dos EUA, era de propor negociações amplas sobre medidas que afetam o fluxo de investimentos, inclusive introduzindo os princípios de Nação Mais Favorecida e de tratamento nacional para a área de investimentos. A posição dos países em desenvolvimento era de que o tema investimentos estava fora do GATT, mas que se fosse introduzido nas negociações deveria também incluir temas como as práticas das multinacionais que afetam o comércio, como transferência de recursos via preços, práticas comerciais restritivas e transferência de tecnologia. Desde o lançamento da Rodada em 1986, os países em desenvolvimento exerceram grande pressão para restringir as negociações do tema investimento apenas aos efeitos considerados restritivos e distorcivos ao comércio", V. THORSTENSEN, (nota 3), p. 102.
} 
sobre Investimentos acabou não tendo a abrangência pretendida pelos países desenvolvidos, de outro, vedou a aplicação por parte dos membros da OMC de medidas de investimentos inconsistentes com os dispositivos do Artigo III (tratamento nacional) e do Artigo XI (restriçōes quantitativas) do GATT. ${ }^{14}$ Ou seja: o Acordo sobre Investimentos, conhecido por sua denominação em inglês "Trade Related Investment Measures"-TRIMs, estendeu aos IED o princípio do tratamento nacional (Artigo III) e estabeleceu a obrigação de eliminação de restrições quantitativas (Artigo XI). Muito embora as disposições do Acordo TRIMs sejam essencialmente uma "reafirmação" da aplicação das regras do GATT, para usar a expressão de Cláudia Perrone-Moisés, elas limitaram, dessa vez com muito maior eficácia, a capacidade dos Estados de estipular requisitos de desempenho ou de comércio exterior aos investidores estrangeiros (i.e., fazer política industrial), razão pela qual, como se verá mais adiante, têm sido muito questionadas sobretudo por países em desenvolvimento, como o Brasil, que defendem sua flexibilização.

Outros instrumentos de particular relevância para os IED que fazem parte da OMC são o Acordo Geral sobre o Comércio de Serviços (GATS) e o Acordo sobre Aspectos de Propriedade Intelectual relacionados ao Comércio (TRIPs). No caso do GATS, como é crescente o volume de IED no setor, especialmente na modalidade 3 (presença comercial, i.e., serviços prestados por empresa de um Estado-Membro que se encontra comercialmente em território de outro Estado-Membro), prevê-se que os Estados-Membros concedam tratamento não menos favorável aos IED daquele que concedem a seus próprios serviços e prestadores. Já o TRIPs estabelece regras mínimas de proteção de patentes, "copyrights", marcas e desenhos industriais, que devem ser incorporadas à legislação interna de todos os Estados-Membros. Na prática, restringe ainda mais a possibilidade de transferência de tecnologia aos países em desenvolvimento, como observado em relatório da Comissão de Direitos Humanos da ONU: "Granting WTO international jurisdiction over TRIPs would restrict, not liberalize, intellectual property rights. This process is likely to create global monopolies beneficial to TNCs [corporaçōes transnacionais] at the cost of public interest.

\footnotetext{
${ }^{14}$ Prescreve o Artigo XI do GATT: "Nenhuma parte contratante instituirá ou manterá, para a importação de produto originário do território de outra parte contratante, ou para a exportação ou venda para exportação de um produto destinado ao território de outra parte contratante, proibições ou restrições a não ser direitos alfandegários, impostos ou outras taxas, quer a sua aplicação seja feita por meio de contingentes, de licenças de importação ou exportação, quer por outro qualquer processo." Como salientado por J. H.JACKSON, o Acordo "confined its attention to just a few specific measures that had proven somewhat troublesome in past trade policy disputes and discourse. Basically, the agreement reaffirms the national treatment obligation, and the prohibition on quantitative restrictions, as related to particular types of investment measures". In The World Trading System: law and policy of International Economic Relations, $2^{2}$ ed., Cambridge, Massachusetts, Londres, Inglaterra, The MIT Press, 1997, pp. 316-317.
} 
The protection of intellectual property rights would render impossible the dissemination of information on the production of new inventions, even in the area of ecologically sound technologies and health".

Insatisfeitos com o fato de o Acordo TRIMs regular medidas de investimento relacionadas apenas ao comércio de bens, os países desenvolvidos prosseguiram em sua tentativa de atingir uma liberalização mais ampla, isto é, estabelecer um quadro normativo no âmbito da OCDE que abrangesse e conferisse maior proteção a todos os tipos de investimentos estrangeiros, inclusive os de "porfolio" ou indiretos. Dentre os temas que, a partir de 1995, têm sido negociados na OCDE com vistas à celebração de um MAI, destacam-se: (i) definição de investimento e alcance geográfico de aplicação do MAI; (ii) tratamento da nação mais favorecida, tratamento nacional e transparência, exceções gerais, derrogações temporárias e reservas; (iii) requisitos de desempenho e incentivos aos investimentos, tecnologia, pesquisa e questōes de desenvolvimento; e (iv) resolução de controvérsias.

A adoção de uma liberalização mais ampla também voltou a ser objeto de intensas negociações no âmbito da OMC durante a Conferência Ministerial de Cingapura em 1996. Na ocasião, foi criado um Grupo de Trabalho sobre Comércio e Investimentos com o propósito de analisar e debater temas, tais como transparência, não-discriminação e solução de controvérsias, que pudessem ser consubstanciados em um MAI. Durante a Conferência Ministerial de Doha, em 2001, foi definido um mandato para a negociação de um MAI. Contudo, o tema nem sequer foi incluído na pauta de negociações da Conferência Ministerial de Cancun realizada dois anos mais tarde em 2003.

\section{O Acordo Trims e os países em desenvolvimento}

O Acordo TRIMS não define medidas de investimentos relacionadas ao comércio. Fornece apenas no Anexo I uma lista ilustrativa de medidas que, nos termos do parágrafo $2^{\circ}$, do Artigo $2^{\circ}$, são incompatíveis com a obrigação de conferir tratamento nacional consignada no parágrafo $4^{\circ}$, do Artigo III, e com a obrigação de eliminação geral das restriçôes quantitativas previstas no parágrafo $1^{\circ}$, do Artigo XI, do GATT, a saber: (i) exigência de aquisição pelo investidor de produtos locais na produção (conteúdo local); (ii) limitação das importações a um porcentual das exportações; (iii) restrições ao acesso de

\footnotetext{
${ }^{15}$ Comissão de Direitos Humanos da ONU. Relatório do Secretário Geral. "The Realization of Economic, Social and Cultural Rights. The impact of the activities and working methods of transnational corporations on the full enjoyment of all human rights, in particular economic, social and cultural rights and the right to development, bearing in mind existing international guidelines, rules and standards related to the subject matter." E/CNSub.2/ 1996, p. 69 c), apud C. PERRONE-MOISÉS, (nota 2), p. 41.
} 
divisas estrangeiras e a importações; e (iv) imposição de metas ou compromissos de exportação (desempenho exportador).

Carreau e Juillard extraem duas conseqüências dessa lista ilustrativa. De um lado, dizem eles, "le choix des illustrations que donne la liste indicative semble indiquer que l'accord ne condamne que les seules M.I.C. [medidas de investimento relacionadas ao comércio] qu'il énumère, parce que ce sont les seules qui s'avèraient incompatibles avec les Articles III:4 et XI:1. Mais d'autre part, ces illustrations ne sont jamais que des illustrations, et elles ne préjugent donc pas de ce que serait la position des instances de l'O.M.C., vis-à-vis d'autres M.I.C. qui pourraient, elles aussi, s'avèrer incompatibles avec l'Article III: ou avec l'Article XI:1".

Muito embora tenha sido conferida aos países em desenvolvimento a possibilidade de deixar de aplicar temporariamente os dispositivos do Acordo TRIMS nos casos relacionados a problemas na balança de pagamentos ou em face da necessidade de proteção a industrias emergentes, não se pode negar que seu espaço para utilização desse importante instrumento de promoção de desenvolvimento industrial que são as medidas de investimento relacionadas ao comércio foi drasticamente reduzido. ${ }^{17}$ É certo que essas medidas não devem ser adotadas de forma a neutralizar ou tornar pouco atraentes as vantagens que os investidores esperam. Contudo, como pondera Rabih Nasser - valendo-se de dados empíricos que mostram que a liberalização não diminuiu a desigualdade nos níveis de desenvolvimento -, "torna-se indefensável a posição de que a renúncia pelos países em desenvolvimento a instrumentos como Trims é mais benéfica a seus interesses do que a manutenção da sua liberdade de aplicar seletivamente tais medidas, de acordo com seu interesse e de forma a não anular os benefícios econômicos buscados pelos investidores" .

De fato, para países em desenvolvimento como o Brasil e seus parceiros do Mercosul, a possibilidade de exigir desempenho exportador e conteúdo local continua sendo importante, como de resto o foi para os atuais países desenvolvidos há algumas décadas.

\footnotetext{
${ }^{16}$ D. CARREAU/F. JUILLARD, (nota 11), pp. 178-179.

${ }^{17}$ Além disso, épreciso lembrar que não há no Acordo TRIMS nenhum dispositivo regulamentando a conduta de empresas transnacionais, cujas atividades podem muitas vezes ferir interesses econômicos locais. Por exemplo: quando a matriz proibe a subsidiária de exportar porque decide privilegiar fontes de produção em outros países dentro de uma estratégia global de produção, mesmo quando a subsidiária dispõe de todas as vantagens comparativas para exportar.

${ }_{18}$ Cf. R. ALI NASSER. A OMC e os Países em Desenvolvimento. São Paulo: Aduaneiras, 2003, p. 194.

${ }^{19}$ Além do já citado exemplo do Canadá, o Japão e a Coréia do Sul fizeram uso constante dessas medidas de política industrial. A Coréia do Sul, aliás, pode-se dizer, "abusou” dessas medidas para montar seu parque automotivo. Também o Brasil utilizou-se dessas medidas por meio do Befiex, mecanismo usado nas décadas de 70 e 80 para induzir companhias nacionais e estrangeiras a exportar parte de sua produção relativa ao que importavam.
} 
Como precedentemente mencionado, o governo brasileiro encomendou alguns estudos para o estabelecimento de uma política de implantação da TV digital no país. Nesses estudos figuraram algumas propostas de adoção de "offsets" ou contrapartidas, como a exigência de aquisição de conteúdo local para a fabricação de componentes para a TV digital. Se essa política (que não deixa de ser política industrial) tivesse sido implantada nesses moldes, o Brasil poderia ter enfrentado alguns questionamentos na OMC quanto à sua inconsistência vis-à-vis o Acordo TRIMS.

O Brasil vem há muito defendendo a necessidade de flexibilização dessas regras do Acordo TRIMS, de forma a poder adotar medidas de investimento relacionadas ao comércio e impulsionar seu desenvolvimento. Em 2002, o país apresentou na OMC, juntamente com a Índia, proposta de flexibilização dessas regras, a qual contou ainda com o apoio da Argentina, Colômbia e Paquistão, dentre outros. Brasil e Índia basearamse em estudos da própria OMC e da UNCTAD mostrando que as "Trims" foram importantes para os países ricos nas fases iniciais de desenvolvimento. Ao defender a flexibilização do Acordo TRIMS, o embaixador do Brasil junto à OMC, Felipe Seixas Corrêa, "argumentou que o grande problema na implementação de Trims é que suas regras são impostas a todos da mesma maneira, sem distinguir o estágio de desenvolvimento de cada país. Assim, as enormes disparidades tecnológicas, sociais, regionais e ambientais entre os países "tornam difícil, senão impossível, para o Acordo de Trims gerar benefícios equilibrados para todos". ${ }^{20}$ Essa proposta apresentada por Brasil e Índia tem dentre seus objetivos alterar o Acordo TRIMS para: (i) promover a indústria doméstica com alto valor agregado; (ii) estimular transferência de tecnologia; (iii) aumentar a capacidade de exportação; (iv) promover pequenas e médias empresas e gerar empregos.

Vale notar que, em novembro de 2003, o governo brasileiro divulgou sua nova política industrial consubstanciada em documento intitulado "Diretrizes de Política Industrial, Tecnológica e de Comércio Exterior”. Essas Diretrizes parecem não contrariar o Acordo TRIMS na medida que não vinculam incentivos a investimentos. Nesse sentido, aliás, salienta-se no documento que a implementação da política, em sintonia "com a postura do governo federal de respeitar contratos e acordos firmados", "como de hábito respeitará os compromissos assumidos no plano internacional, em particular nos foros multilaterais (OMC) e regionais (Mercosul e outros acordos com países sul-americanos)". O documento elege semicondutores, software, fármacos e medicamentos e bens de capital como estratégicos para implementação de sua política.

${ }^{20}$ Ver Jornal Gazeta Mercantil de 15/10/2002, p. A-6. 


\section{A retomada das negociações sobre investimentos na OMC e na ALCA. A questão dos BITs. A situação no Mercosul}

A partir de 2005, quando forem retomadas provavelmente as negociações tanto na OMC quanto na ALCA, os países desenvolvidos deverão voltar a insistir na celebração de acordos que possam conferir aos investidores ampla proteção a seus investimentos nas fases de pré e pós-estabelecimento. Temas complexos como definição ampla de investimentos (o que incluiria também os indiretos), transparência, não-discriminação, exceções e salvaguardas para balanço de pagamentos deverão figurar novamente na agenda desses países. Na OMC, deverá continuar havendo grande objeção a qualquer tipo de flexibilização das regras do Acordo TRIMS, uma vez que, segundo a maioria dos países desenvolvidos, este já incorpora tratamento especial para os países em desenvolvimento. $\mathrm{Na}$ ALCA, da mesma forma, o tema da flexibilização do recurso às “Trims" deverá ser posto de lado pelos Estados Unidos. Os Estados Unidos deverão insistir na mesma tese defendida na OMC de que o debate sobre esse assunto "já acabou". ${ }^{21}$ A exemplo do que fizeram durante a XVII Reunião do Comitê de Negociaçôes Comerciais em Puebla, no México, em 2004, deverão continuar a defender a inclusão de disciplinas rígidas de garantia para os investidores similares às do Capítulo 11 do Nafta, dentre as quais, tratamento nacional e cláusula de nação-mais favorecida, lista negativa para o pré e pósestabelecimento, garantias contra expropriação e nacionalização de investimentos, bem como, evidentemente, mecanismos de solução de controvérsias que colocam Estados e investidores privados em situação de igualdade hierárquica.

No tocante aos BITs, muito embora o Brasil seja signatário de muitos deles, não há previsão de que venham a ser ratificados. A Argentina, ao contrário, é signatária de 54 BITs, dos quais 43 se encontram em vigor.

No âmbito do Mercosul, há dois Acordos sobre Investimentos: o "Protocolo de Colônia para a Promoção e Proteção Recíproca de Investimentos", assinado em 17 de janeiro de 1994 ("Protocolo de Colônia"), e o "Protocolo de Buenos Aires sobre Promoção e Proteção de Investimentos Provenientes de Estados não-Membros do Mercosul”, celebrado em 05 de agosto de 1994 ("Protocolo de Buenos Aires").

O Protocolo de Colônia regulamenta os investimentos de investidores originários de um membro no território de outro membro do Mercosul. Adota um amplo conceito de investimento, que inclui, em particular, ainda que não exclusivamente, a propriedade de bens móveis e imóveis, ações e quotas societárias e qualquer outro tipo de participação em

${ }^{21}$ Ver a respeito Gazeta Mercantil de 15/10/2002, p. A-6. 
sociedades, bem como direitos de propriedade intelectual (direitos de autor e de propriedade industrial).

Dispõe, também, sobre o ingresso e estabelecimento, tratamento, proteção, transferência de fundos, sub-rogação de direitos no caso de utilização de garantias e solução de controvérsias. No caso de ingresso, prevê que cada "Parte Contratante promoverá os investimentos de investidores das outras Partes Contratantes e os admitirá em seu território de maneira não menos favorável que os investimentos de seus próprios investidores ou investimentos realizados por investidores de terceiros Estados." (Artigo 2º, 1); quanto ao tratamento estabelece que cada "Parte Contratante assegurará em todo momento um tratamento justo e eqüitativo aos investimentos de investidores de outra Parte Contratante e não prejudicará sua gestão, manutenção, uso, gozo ou disposição por meio de medidas injustificadas ou discriminatórias." (Artigo $3^{\circ}, 1$ ); e, no tocante às transferências estipula que cada "Parte Contratante outorgará aos investidores de outra Parte Contratante a livre transferência dos investimentos e rendimentos", e, em particular, embora não exclusivamente, de: (i) capital e somas adicionais necessárias para a manutenção e o desenvolvimento dos investimentos; (ii) proventos, lucros, rendas, juros, dividendos e outras receitas correntes; e (iii) remunerações dos nacionais de uma Parte Contratante que tenham obtido autorização para trabalhar em conexão com um investimento (Artigo 5º, 1).

Já o Protocolo de Buenos Aires tem como objetivo harmonizar o tratamento conferido pelos Estados-Membros aos investimentos originários dos Estados não-Membros. Trata-se de tarefa difícil, uma vez que, como visto, enquanto a Argentina já celebrou e ratificou vários BITs, o Brasil não ratificou nenhum desses acordos bilaterais.

Assim, nenhum desses Protocolos encontra-se em vigor por falta de ratificação pelos Estados-Membros do Mercosul.

\section{Conclusões}

Não há evidências conclusivas de que Acordos de Investimentos possam levar a um aumento de IED. Estatísticas demonstram que, não obstante muitos países em desenvolvimento terem firmado BITs, eles ainda são destinatários de menos de $1 / 3$ do total do fluxo de IED no mundo. Não constitui, portanto, a participação de acordos multilaterais, regionais ou bilaterais, fator determinante na maior ou menor atratividade de IED. Enquanto em países de menor desenvolvimento relativo da África, por exemplo, a baixa atratividade se deve, dentre outros fatores, à instabilidade política, à ausência de infraestrutura e à reduzida dimensão dos mercados domésticos, em países emergentes, como o Brasil, as oscilações no fluxo de IED decorrem, como precedentemente mencionado, da alta carga tributária, da enorme burocracia, do crédito caro, da má distribuição de renda, do baixo nível de poupança e do ambiente regulatório, dentre outras razões. 
As atuais propostas de liberalização dos investimentos internacionais no plano multilateral (MAI) da OMC ou no regional da ALCA são muito direcionadas em favor dos países desenvolvidos. Elas restringem com maior rigor ainda o espaço para adoção de políticas industriais que, como visto, continuam sendo um importante mecanismo de estímulo ao desenvolvimento. Por outro lado, segundo relatório da UNCTAD de 2003, a proliferação de BITs também está levando a uma redução da capacidade dos países em desenvolvimento de adotar políticas industriais capazes de coordenar melhor a atuação das empresas transnacionais em seus territórios.

É por isso que, para os países em desenvolvimento, o desafio mais importante é encontrar um equilíbrio entre a contribuição potencial dos Acordos de Investimentos para o aumento da atratividade e dos fluxos de investimento e a preservação do espaço e da capacidade de perseguir políticas industriais orientadas para o desenvolvimento. A flexibilização do Acordo TRIMS da OMC representará um grande passo nesse sentido. No caso do Mercosul, a harmonização do tratamento conferido pelos Estados-Membros aos investimentos originários dos Estados não-Membros, tal como previsto no Protocolo de Buenos Aires, também constituiria medida de grande importância.

\section{Bibliografia}

BAPTISTA, Luiz Olavo. Os investimentos internacionais no Direito Comparado e Brasileiro. Porto Alegre: Livraria do Advogado Editora, 1998, p. 30-31.

BEVIGLIA, Zampetti; FREDRIKSSON, T. The development dimension of investment negotiations in the WTO: challenges and opportunities. Journal of World Investment, v. 4, n. 3, p.401, jun. 2003.

CARREAU, D.; JUILLARD, F. Droit International Économique, 4. ed. Paris: L.G.D.J., 1998, p. 174.

DIAS, B. Figueiredo. Os impactos dos acordos internacionais sobre investimentos estrangeiros diretos na legislação brasileira. Dissertação (Mestrado) - Faculdade de Direito da Universidade de São Paulo, 2004, p. 36.

JACKSON, J. H. The World Trading System: law and policy of International Economic Relations. 2. ed. Londres, Inglaterra, Cambridge, Massachusetts, the MIT Press, 1997, p. 316-317.

KLEIN, V. Questões acerca de uma Política Industrial no Mercosul. In: W. MENEZES (Org.). Estudos de Direito Internacional. Curitiba, Juruá, v. II, 2004, p. 506.

NASSER, R. A., A OMC e os paises em desenvolvimento. São Paulo: Aduaneiras, 2003, p. 194.

PERRONE-MOISÉS, C. Direito ao desenvolvimento e investimentos estrangeiros. São Paulo: Ed. Oliveira Mendes, 1998, p. 24. 
THORSTENSEN, V. OMC - Organização Mundial do Comércio: as regras do comércio internacional e a Nova Rodada de Negociações Multilaterais. 2. ed. São Paulo: Aduaneiras, 2001, p. 102/103.

\section{Sites}

UNCTAD - www.unctad.org.

JORNAL GAZETA MERCANTIL - www.gazeta.com.br 